\title{
IMPACT OF TABBACO INDUSTRY IN THE PERFORMANCES OF US ECONOMY
}

\author{
Fulop Agota, Acquisition Manager for SHAKI COMP Ltd, Romania
}

dx.doi.org/10.18374/JIMS-20-1.2

\begin{abstract}
Automotive industry is playing an important role in the US economy. We analyze the production of passenger cars in US during the period 1947-2016. The impact of oil price on the number of passenger cars produced is evaluated. Influence of automotive industry on GDP and unemployment rate is evaluated. Regression models are designed and used to generate analysis and conclusions.
\end{abstract}

Keywords: tobacco industry, GDP, regression models, correlations. 